\title{
REPRESENTASI PENDIDIKAN SPIRITUAL ISLAM DALAM NOVEL LAUH MAHFUZ KARYA NUGROHO SUKSMANTO (PENDEKATAN FENOMENOLOGI)
}

\author{
Ichyaa Uluumiddin \\ Yayasan Pondok Pesantren Sirojut Tholibin \\ Jln Bengawan Solo, 02/04, Laren, Lamongan
}

\begin{abstract}
Abstrak: Tujuan penelitian ini adalah Mendiskripsikan hakikat pendidikan spiritual Islam yang terkandung dalam novel Lauh mahfuz karya Nugroho Suksmanto. Dan Merepresentasi pendidikan spiritual Islam yang terkandung dalam novel Lauh mahfuz karya Nugroho Suksmanto dengan realita pendidikan spiritual di masyarakat. Penelitian ini menggunakan metode kualitatif yang bersifat deskriptif Artinya, penulis membahas dan mengkaji novel tidak mengunakan angka, tetapi menekankan pada diskripsi, yang mendiskripsikan novel LauhMahfuz. Data penelitian ini adalah Novel yang berjudul Lauh Mahfuz karya Nugroho suksmanto. Teknik pengumpulan data yang digunakan adalah teknik dokumentasi, teknik simak, dan teknik catat pada analisis data yang dilakukan. Langkah-langkah: membaca Novel, mengambil data, dan penyimpulan. Hasil penelitian ini menunjukkan bahwa hakikat pendidikan spiritual Islam yang terkandung dalam novel Lauh Mahfuz karya Nugroho suksmanto mempunyai beberapa aspek yaitu: aspek hakikat Pendidikan akidah dan aspek hakikat pendidikan sariah.
\end{abstract}

Kata kunci: hakikat pendidikan, hakikat spiritual, Islam.

Abstract: The purpose of this study is to describe the nature of Islamic spiritual education contained in the novel Lauh mahfuz by Nugroho Suksmanto, and to describe the Representation of Islamic spiritual education contained in the novel Lauh Mahfuz by Nugroho Suksmanto with the reality of spiritual education in the community. This study uses qualitative methods that are descriptive. That is, the reasearcher discusses and studies novels not using numbers, but emphasizes the description, which describes the novel Lauh Mahfuz. The data of this study is a novel entitled Lauh Mahfuz by Nugroho suksmanto. Data collection techniques used are documentation techniques, see techniques, and note-taking techniques in the data analysis performed. Steps: reading novels, taking data, and summarizing.The results of this study indicate that the nature of Islamic spiritual education contained in the novel Lauh Mahfuz by Nugroho suksmanto has several aspects, namely: the essence of faitheducation which and aspects of Shari'ah education which.

Keywords: the assence of education, the assence of spiritual, Islam

\section{PENDAHULUAN}

Pendidikan adalah suatu suatu proses mendewasakan manusia, atau dengan kata lain memanusiakan manusia. Muchtar $(2008 ; 01)$ menyatakan bahwa pendidikan dapat mengubah manusia dari tidak tahu menjadi tahu, dari tidak bijak menjadi bijak. Pendidikan dapat mengubah semuanya. Pada dasarnya pendidikan merupakan pembelajaran yang beranggapan bahwa sejak dilahirkan anak sudah memiliki potensi-potensi, 
baik potensi untuk berfikir, berbuat, memecahkan masalah ataupun potensi untuk berkembang sendiri. Semisal kita ibaratkan pesawahan maka pendidikan bisa di ibaratkan persemian, yang berfungsi untuk menciptakan lingkungan yang menunjang dan agar terhindar dari hama.

Engkoswara dan Komariah (2012:7) menyatakan pendidikan yang mengembangkan kematangan beragama dapat menjadikan individu sebagai seseorang yang memiliki kekuatan spiritual question. Kematangan beragama tidak hanya belajar tentang keimanan saja. Masih banyak ilmu yang perlu dikaji agar individu tersebut bisa mempunyai kekuatan spiritual question seprti keilmuan imaniyah, ruhiyah, fikriyah, akkiriyah, akhlaq, irodah, badriyah, jinsiyah dan lain sebagainya.

Didalam sebuah karya sastra yang berwujud novel yang berjudul Lauh Mahfuz yang dibuat oleh Nugroho Suksmanto ini menceritakan seseorang yang bernama Panji. Panji adalah seseorang yang mengalami pendidikan yang unik yaitu pendidikan dalam bawah sadar dan dialam nyata. Yang mana pendidikan tersebut adalah pendidikan yang bersifat spiritual (Rohaniah, Batiniah) dengan kata lain pendidikan yang bersifat ketuhanan. Dalam pendidikan itu mempunyai tujuan dalam individual seorang panji yang menuju pada sosial kemasarakatan yakni negara kesatuan Indonesia. Dalam pendidikan spiritual dalam novel lauh mahfuz sendiri dijelaskan tentang spiritual islam dan spiritual kristen. Dan kedua agama tersebut mempunyai tujuan yang sama, cuman peneliti disini akan hanya menjelaskan dan meneliti tentang spiritual Islam.

Sehingga peniliti menarik judul Representasi Pendidikan Spiritual Islam dalam Novel Lauh Mahfuz karya
Nugroho Suksmanto dengan Pendekatan Fenomenologi Sastra

\section{METODE PENELITIAN}

Penelitian ini menggunakan metode deskriptif kualitataif dengan pendekatan fenomenologi. Metode kualitatif memberikan perhatian terhadap data alamiah, data dalam hubunganya dengan konteks keberadaanya. Penelitian kualitatif adalah prosedur penelitian yang menghasilkan data diskriptif berupa katakata tertulis atau lisan dari orang-orang prilaku yang diamati (Bogdan dan Taylor dalam Moleong, 1990: 3)

Data dalam penelitian ini adalah data kualitatif. Data kualitatif berupa katakata atau gambar bukan angka-angka. Berdasarkan pernyataan tersebut, data penelitian ini berupa frase, kalimat, paragraf dalam novel Lauh mahfuz yang berisi tentang pendidikan spiritual.

Teknik analisis data penelitian ini menggunakan langklah-langkah sebagai berikut: Langkah 1: membaca novel Lauh mahfuz karya Nugroho Suksmanto untuk memahami struktur global novel tersebut secara berulang-ulang dan cermat, kata demi kata dan kalimat demi kalimat, Langkah 2: mengambil data yang berkaitan dengan hakikat pendidikan spirtitual Islam yang terdapat dalam novel Lauh mahfuz karya Nugroho Suksmanto, Dan Langkah 3: menganalisis data yang berkaitan dengan hakikat pendidikan spiritual Islam yang terdapat dalam novel Lauh mahfuz karya Nugroho Suksmanto.

\section{ANALISIS DAN PEMBAHASAN Hakikat Pendidikan Spiritual Islam}

Spiritual memang bukan agama. Akan tetapi, ia memiliki hubungan dari segi nilai-nilai keagamaan yang tidak dapat dipisahkan. Titik singgung antara spiritualitas dengan agama tampaknya memang tidak dapat dinafikan 
sepenuhnya. Keduanya menyatu dalam nilai-nilai moral, adapun nilai-nilai moral itu tergolong pada nilai utama dalam setiap agamaKetika kita membahas spiritual maka kita akan membahas Agama atau religi. Agama tersebut yang mengajarkan nilai-nilai akidah, syariah, dan akhlak kemudian dari tiga nilai akan diaplikasikan di sebuah jalan yang biasanya kita sebut Tariqah sehingga kita bisa mencapai hakikat. Disinilah letak spiritual yang mana hubungan antara manusia dengan tuhanya.

Pendidikan yang bersumber pada Agama ini selalu mengacu pada AlQuran dan Al-Hadist, ketika tidak ada dalam Al-Quran ataupun Al-Hadis maka ulama' akan menggunakan Ijma' dan Kias. Sehingga disitu kita buisa membenarkan atau menyalahkan berbuatan manusia. Manusia yang selalu menginginkan kebenaran yang hakiki maka tidak akan meninggalkan Al-Quran, Al-hadis dan seorang Ulama'. Ulama' tersebut yang bisa menentukan ijma' dan kias dalam batsul matsail dalam permasalahan-permasalahan yang sulit dibuktikan kebenaranya. Sehingga manusia yang selalu memegang teguh AlQuran, Al-Hadist akan mempunyai kebenaran yang Hakiki dan sifat spiritual yang tinggi. Spiritual dalam kamus besar bahasa Indonesia memiliki arti berhubungan dengan atau sifat kejiwaan (Rohani dan Batin) maka spiritual yang tinggi adalah kerohanian dan kebatinan yang dekat bahkan menyatu pada sang pencipta yaitu Allah SWT.

Engkoswara dan Komariah (2012:7) menyatakan pendidikan yang mengembangkan kematangan beragama dapat menjadikan individu sebagai seseorang yang memiliki kekuatan spiritual question. Kematangan beragama tidak hanya belajar tentang keimanan saja. Masih banyak ilmu yang perlu dikaji agar individu tersebut bisa mempunyai kekuatan spiritual question seperti keilmuan sariah dan akidah. Ilmu syariah hablum-minallah yang biasa kita sebut Rukun Islam itu ada lima yaitu: syahadah, sholat, zakat, puasa, dan haji bila mampu. Sebelum membahas ilmu syariah maka kita perlu memahami betul ilmu akidah, agar apa yang kita lakukan sesuai apa yang kita yakini.

\section{Pendidikan akidah}

Peneliti menemukan ada beberapa pendidikan yang harus laksanakan sejak dini. Di antara pendidikan tersebut adalah pendidikan aqidah. Seperti yang tertulis dalam novel Lauh Mahfuz karya Nugroho Suksmanto di bawah :

"Setiap agama atau kepercayaan memiliki dua aspek, yaitu sikap atau yang berhubungan dengan akidah dan tindakan yang erat hubungan dengan syariat." Dari semua penjelasan yang diutarakan oleh Sekh Ibnu Khalaf kepada Panji, Panji hanya terdiam saja untuk memahaminya. (Nugroho, 2012 : 98)

Dalam penjelasan sekh Ibnu Khalaf kepada panji tentang akidah yang berhubungan dengan syariah maka peneliti dapat memberi kesimpulan, Akidah adalah keyakinan dasar yang menguatkan atau meneguhkan jiwa sehingga jiwa terbebas dari rasa kebimbangan atau keraguan, di dalam islam disebut iman. Peneliti merumuskan bahwa keimanan ada enam dengan bukti Hadist Rasul.

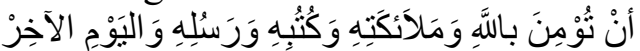

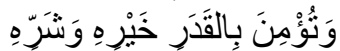

Artinya: Ketika jibril menanyakan kepada Rasul tentang keimanan: maka rasul menjawab, : hendaklah engkau mengimani Allah, para malaikat Allah, kitab-kitabnya, para Rasul nya juga hari kiamat. Hendaknya engkau mengimani qadar yang baik dan puruk dari Allah" (HR Muslim. Saheh Muslim. tt. Jus 1. 30)

\section{Iman Kepada Allah}

Iman kepada Allah, bahwasanya menyatakan kalau Allah itu ada dan segala sifat keagungan dan 
kesempurnaanya. Dalam hal ini keimanan kepada Allah tidak dapat langsung dilogikakan dengan keterbatasan akal manusia. Bahkan islampun melarang manusia untuk berfikir langsung tetntang Zat Allah. Karena Zat Allah berada diluar kemampuan akal untuk menjangkaunya.Iskandar (2015: 03) menyatakan rasulullah SAW pernah bersabda

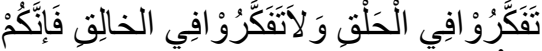

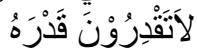

Artinya: berfikirlah kalian tentang mahluk Allah, tetapi jangan kalian berfikir tentang Dzat Allah, sebab kalian tidak akan sanggup mengira-ngira Hakikatnya yang sebenarnya. (HR Abu Nu'aim. Muatha'. tt . 93.)

\section{Iman Kepada Malaikat Allah}

"Bahasa perasaan yang puitis, simbolik dan metaforik, menyimpan rahasia tuhan yang perlu diungkap maknanya. Salah satu yang perlu kita maknai adalah penciptaan malaikat, yang dalam firman dikatakan berasal dari cahaya. Cahaya adalah metamorfosis energi atau kekuatan yang bersifat mencerahkan dan menerangi. Tentu yang dimaksudkan adalah berkaitan dengan hal mencerahkan atau menerangi jiwa manusia, sebagaimana tujuan agama sebagai ajaran moral." (Nugroho, 2012 :128-129)

Dari penjelasan penjelasan syehk Ibnu Khalaf kepada Panji mengatakan malaikat bersifat mencerahkan yang berhubungan dengan jiwa manusia.

\section{Iman Kepada Rasul-Rasul Allah}

Iskandar menyatakan (2015:39)

Rasul adalah seorang yang diutus Allah dengan Syariat yang baru untuk menyeru manusia kepadanya, Nabi orang yang diutus Allah untuk menetapkan Syariah rasul-rasul sebelumnya. Ketika kita melihat kesamaanya antara nabi dan rasul maka mereka sama-sama untuk menyampaikan syariat , ketetapan- ketetapan dari Allah. Yang menjadi pembeda adalah seorang rasul syariah baru dan nabi syariah lama. Seperti yang tertulis dalam Novel Lauh Mahfuz karya Nugroho Suksmanto:

"Agama samawi berlandaskan keyakinan tentang peran umat pilihan yang disebut Nabi sebagai utusan tuhan. Sementara agama lain menganggap orang suci pembawa agama atau ajaran moral, sebatas menerima ilham atau wahyu untuk menyampaikan ajaran budi pekerti. (Nugroho, 2012 :130)

Penjelasan syehk Ibnu Khalaf kepada Panji, mengatakan Agama Samawi yang mempunyai keyakinan Nabi sebagai utusan Tuhan. Kita simpulkan makna keimanan yang tertulis di atas bahwa: kita kita malakukan kesaksian yang disebut syahadah daisitu ada dua kalimat sahadah, syahadah pertama kesaksian kepada Allah dan syahadah kedua kesaksian kepada utusan Allah Muhammad SAW. Ketika kita menyaksikan bahwa Muhammad adalah utusan Allah maka kita harus meniru semua prilaku rasul dalam artian melakukan apa saja yang diperintahkan oleh rasul dan meniunggalkan apa yang dilarang oleh rasul. Itulah bukti kesaksian kita dan cinta kita kepda rasul.

\section{Iman Kepada Kitab Allah}

Ketika kita iman kepada Rasul maka secara otomatis kita akan mengimani apa saja yang dibawa oleh rasul, seperti halnya Al-Quran adalah wahyu yang diturunkan kepada Rasul oleh Allah untuk disampaikan kepada umat manusia. Seperti halnya yang terkutip dalam novel Lauh Mahfuz karya Nugroho Suksmanto Ketika kita mengimani Al-Quran:

"Kita ketahui bahwa Al-Quran sebagai firman Tuhan diturunkan dalam bahasa perasaan, yang sangat puitis. Peran utamnaya adalah menyampaikan kabar 
gembira, penjelasan dan peringatan." (Nugroho, $2012: 128$ )

\section{Iman Kepada Hari Kiamat}

Semua alam memiliki massa, dari yang benyawa hingga yang tidak bernyawa mempunyai masa. Seperti contoh umat manusia jasadnya tidak akan abadi bahkan pepohonan, dan alam yang lain sama halnya tidak akan pernah abadi, pasti akan menuai kehancuran, maka jasad akan menuai kehancuran yang namanya meninggal dunia dan juga pepohonan dan alam sekitar akan menuai keghancuran. Maka bumi dan isinya bahkan alam sekitar juga mempunyai masa. Ini yang disebut hari kiamat. Ketika kita memahami tentang kehancuran Alam (kiamat) maka tidak ada hari lagi didunia ini, dan kiata akan menempuh kehidapan baru di akhirat. seperti yang tertuang dalam Novel Lauh mahfuz karya nugroho Suksmanto yang berbunyi:

"Iman kepadaa hari kiamat yang
dimaksudkan oleh agama adalah bukan
sekedar percaya pada kehancuran yang
menyebabkan kepunahan segala hal,
melainkan sebagai titik awal memasuki
kehidupan baru, yang dinamakan
kehidupan akhirat. Pilihanya ada dua
yaitu neraka atau surga." (Nugroho, 2012
:135)

Seykh Ibnu Khalaf menjelaskan kepada panji bahwa iman kepada hari kiamat merupakan proses perpindahan alam yang akan dialami oleh semua insan, Iskandar (2015:48) menyatakan seorang muslim ber iman bahwa kehidupan didunia akan musnah dan berahir, kemudian berganti dengan kehidupan kedua di alam akhirat.

\section{Iman Kepada Qada dan Qadar}

Hidup ini memang penuh dengan warna. Dan ingatlah bahwa hakikat warna-warni kehidupan yang sedang kita jalani di dunia ini telah Allah tuliskan (tetapkan) dalam kitab "Lauhul Mahfudz" yang terjaga rahasianya dan tidak satupun makhluk Allah yang mengetahui isinya. Semua kejadian yang telah terjadi adalah kehendak dan kuasa Allah SWT. Begitu pula Kematian, kelahiran, rizki, nasib, jodoh, bahagia, dan celaka telah ditetapkan sesuai ketentuan-ketentuan Ilahiah yang tidak pernah diketahui oleh manusia Iskandar (2015:61) menyatakan seorang muslim beriman dan yakin bahwa semua keadaan didunia ini pasti deketahui oleh Allah karena Allah maha mengetahui (Al-Alim) baik kejadian yang telah, sedang, maupun yang akan terjadi.. seperti yang dijelaskan dalam novel Lauh Mahfuz karya Nugroho Suksmanto

"Qada yang meliputi juga kodrat adalah keputusan allah sejak zaman azali tentang ada dan tidak adanya sesuatu. Adapun kodar yang meliputi juga takdir, adalah penciptaan allah terhadap sesuatu dengan cara tertentu dan waktu tertentu." Dari semua penjelasan yang diutarakan oleh Sekh Ibnu Khalaf kepada Panji, Panji hanya terdiam saja untuk memahaminya (Nugroho, 2012 :139)

\section{Hakikat Pendidikan Syariah}

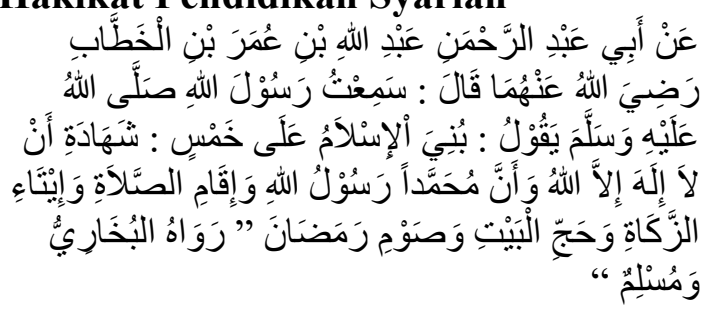

Artinya: Dari Abu 'Abdurrahman 'Abdullah bin 'Umar bin Al-Khattab radhiyallahu 'anhuma, ia mengatakan bahwa ia mendengar Rasulullah shallallahu 'alaihi wa sallam bersabda,"Islam dibangun di atas lima perkara: bersaksi bahwa tidak ada yang berhak disembah melainkan Allah dan bersaksi bahwa Muhammad adalah hamba dan utusan Allah; menunaikan shalat; menunaikan zakat; menunaikan haji ke Baitullah; dan berpuasa Ramadhan." (HR. Muslim. Sahih muslim.tt . Jus 1.16) 
Dalam pendidikan syariat yang mengarah pada hablum-minallah yang kita sebut sebagai rukun islam ada lima yaitu: Syahadah, Sholat, Zakat, puasa, Haji bila mampu seperti yang dikartakan dalam Novel Lauh Mahfuz karya Nugroho Suksmanto menggambarkan:

"Manifestasi hablum-minallah adalah sebagai mana diperintahkan Tuhan, yaitu dengan mendirikan shalat. Syariat lain yang melengkapai rukun islam adalah: menunaikan zakat, Puasa pada bulan ramadlan, dan naik haji." (Nugroho, $2012: 107-108$ )

\section{Syahadah}

Dari sini inti dari keimanan kita kemudian kita lafalkan untuk menjadi persaksian kepada tuhan yang maha Esa dengan lafal

$$
\begin{aligned}
& \text { أثهد أن لا اله الا الله و أثهد ان محمد رسول الله 'Saya bersaksi bahwa tiada } \\
& \text { Artinya: 'Sahan selain Allah dan saya bersaksi } \\
& \text { Tuhahwa Muhammad adalah rasul (utusan) } \\
& \text { bahwah. }
\end{aligned}
$$

Syahadah ini diajarkan oleh seluruh nabi-nabi dan rasul-rasul Allah, yang kemudian diikrarkan oleh nabi ibrahim kemudian diwujudkan kiblat yang kita anggap sebagai rumah tuhan yaitu kakbah, seperti yang terkutip dalam novel Lauh mahfuz karya nugroho Suksmanto:

"Dari sinilah perangkat kesaksian tuhan yang maha tunggal oleh ibrahim dan dari sinilah berahir sejarah kenabian yang diemban oleh Muhammad sebagai nabi terahir." (Nugroho, 2012 :104)

Syekh Abu Salaf menjelaskan kepada Panji dan Menuk tentang syahadah atau kesaksian kepada sang pencipta. Didalam syahadah tertuang tiga makna yaitu ikrar, sumpah, perjanjian

\section{Shalat}

Shalat secara bahasa berarti berdo'a. dengan kata lain, shalat secara bahasa mempunyai arti mengagungkan. Sedangkan pengertian shalat menurut syara' adalah ucapan-ucapan dan perbuatan-perbuatan tertentu, yang dimulai dengan takbiratul ihram dan diakhiri dengan salam. Ucapan di sini adalah bacaan-bacaan al-Qur'an, takbir, tasbih, dan do'a. Sedang yang dimaksud dengan perbuatan adalah gerakangerakan dalam shalat misalnya berdiri, ruku', sujud, duduk, dan gerakan-gerakan lain yang dilakukan dalam shalat.

"Setiap agama menuntun umatnya pada suatu perenungan. Perenungan yang mengarahkan batin yang menukik tajam kedalam kalbu dilakukan melalui meditasi. Shalat adalah meditasi tertinggi dalam islam." (Nugroho, 2012 :109)

Syekh Abu Salaf menjelaskan kepada Panji dan Menuk bahwa Shalat adalah ibadah yang paling sering kita lakukan, dalam sehari semalam kita melakukan shalat sebanyak lima waktu. Disebutkan bin Abdul qadir (2015.29) shalat merupakan hubungan hamba denga Roobnya yang wajib dilaksanakan lima waktu sehari semalam, sesuai petunjuk (contoh) Rasulullah SAW. Bahasa lima waktu disini adalah Dluhur, Asar, magrib, Isa', dan subuh.

\section{Zakat}

Zakat menurut syara' adalah memberikan (menyerahkan) sebagian harta tertentu untuk orang tertentu yang telah ditentukan syara' dengan niat karena Allah. Zakat merupakan al-'ibadah almaaliyah al-ijtimaa'iyah (ibadah di bidang harta yang memiliki nilai sosial). Disinilah letak hukum hablumminannas.Hukum zakat yang wajib meniscayakan bahwa zakat bukan semata merupakan bentuk kedermawanan, melainkan bentuk ketaatan kepada Alloh SWT sehingga harus diperhatikan mengenai tata cara pembayaran dan pembagiannya. Seperti yang dikatakan dalam Novel Lauh Mahfuz karya Nugroho Suksmanto:

$$
\text { "Manifestasi Hablum-minannas yang }
$$
paling utama bagi umat islam adalah 
menunaikan zakat, sekalkigus juga refleksi Hablum-minallah, karena merupakakan penghambaan mengikuti perintahnya dalam kaitan qurban atau mengorbankan harta yang dimiliki bagi sesama manusia. Dengan demikian tersirat adanya pengakuan bahwa harta yang dimiliki adalah karunia tuhen semata, yang harus dikembalikan sebagian untuk mensucikan diri sebagaimana yang diperintahkan olehnya." (Nugroho, 2012 :122)

\section{Puasa}

Arti puasa menurut bahasa adalah menahan. Menurut syariat islam puasa adalah suatu bentuk aktifitas ibadah kepada Allah SWT dengan cara menahan diri dari makan, minum, hawa nafsu, dan hal-hal lain yang dapat membatalkan puasa sejak terbit matahari / fajar / subuh hingga matahari terbenam / maghrib dengan berniat terlebih dahulu sebelumnya.

"Puasa atau shaum berarti imsak, yaitu menahan hawa nafsu. Ramadan artinya membakar. Puasa Ramadan adalah upaya melatih diri untuk menahan hawa nafsu untuk membakar dosa-dosa, yaitu dengan menyucikan diri dan hal-hal yang mengotori hati. Hati terkotori oleh nafsu, sehingga puasa dijalani dengan menahan nafsu, yaitu makan, minum, dan menahan diri dan hasrat memperoleh keinikmatan ragawi." (Nugroho, 2012 :370)

\section{Haji}

Ibadah haji ini merupakan ibadah yang wajib tetapi ada Qoyyit. Wajib dilakukan ketika orang tersebut ketika orang tersebut mampu secara fisik dan finansial dijelaskan oleh Bin Abdul Qodir Jawas, $(2015,47)$ : tidak halal bagi seorang muslim menunda ibadah haji apabila ia memiliki badan yang sehat dan harta yang cukup untuk melaksanakan haji dan membiyayai keluarga ketika ia pergi. Haji wajib kita lakukan sekali dalam kurun waktu seumur hiduk kita seperti yang dikatakn oleh Bin Abdul Qodir Jawas, $(2015,46)$ : ibadah haji merupakan kuwajiban yang harus ditunaikan sekali seumur hidup. Ketika qoyyit tersebut terpenuhi maka hukumnya wajib apabila tidak dilaksankan hingga ia meninggal maka akan mendapatkan dosa.Sabiq (tt. 141) menyatakan haji adalah menyengaja pergi kemakkah untuk melakukan thowaf, sa'i, wukuf diarafah, dan rukunrukun hajilainnya dengan niat memenuhi panggilan Allah dan mengharap ridlonya. Seperti yang tertulis dalam novel Lauh Mahfuz karya nugroho Suksmanto:

"Ibadah haji kemudjan memiliki kelengkapan rukun, selain berihram dengan wukuf di Padang Arafah, ditambahi dengan tawaf mengitari Kakbah, sya'ie di antara Bukit Safa dan Marwah dan menggunting rambut, mabit di Mina serta lempar jumrah. "(Nugroho, $2012: 421)$

Panji memahami apa yang di ajarkan oleh syekh Abu Salaf bahwa Dalam ibadah haji terdapat aturan atau tata cara melaksanakan haji yang disebut rukun haji dan juga wajib haji. Dalam melaksanakan ibadah haji keduanya harus dilaksanakan. Namun ada perbedaan di antara keduanya. Yaitu, pada rukun haji jika tidak dilaksanakan, maka hajinya batal atau tidak sah dan harus diulang.

\section{Representasi Pendidikan Spiritual Islam Dalam Novel Lauh Mahfuz Dengan Realita Pendidikan Spiritual Islam Di Masyarakat}

Representasi pendidikan spiritual yang terkandung dalam novel Lauh mahfuz karya nugroho sukmanto dengan realita pendidikan spiritual di masyarakat meliputi beberapa aspek. Hal itu sangat berhubungan erat dengan tata cara berkehidupan dimasyarakat yang baik menurut syariah. Adapun aspek-aspek 
tersebut meliputi: syahadah, shalat, zakat, puasa, dan haji.

\section{Syahadah}

Jika seseorang memasuki ruang yang tetrutup, dia memerlukan password atau kunci untuk membuka pintunya. Demikian juga untuk masuk Islam, seseorang harus terlebih dahulu harus mengucapkan kalimat syahadatain (dua syahadat), yaitu laa ilaaha illallah dan Muhammadurrasuulullah. Inilah kunci Islam itu. Seperti yang diceritakan dalam novel Lauh mahfuz karya nugroho Suksmanto:

"syekh saya ingin shekh menjadi saksi, bahwa saat ini dan selamanya , saya adalah seorang muslim." (Nugroho, 2012 :71)

Menuk memohon kepada syekh Abu salaf agar syekh Abu Salah bisa membimbing menuk bersyahadah dan menjadi saksi bahwa menuk mulai saat ini hingga selamanya menuk menjadi seorang muslim. Kalimat diatas mempunyai arti bahwa seorang yang telah mengucapkan dua kalimat syahadah secara tersirat dia telah berjanji bahwa akan memenuhi perinrtahnya (Allah) dan meninggalkan larangannya dalam kehidupan sehari-hari. Maka kensekwensi dari hal itu dia akan mendapatkan semua yang dijanjikan Allah SWT, baik berupa diterimanya amal di dunia hingga pahala yang melimpah ruah di akhirat kelak. Tanpa kunci itu, semua amal -sebaik apapun dalam pandangan manusia- tidak ada nilainya di hadapan Allah SWT. Hal ini sering kita temukan dalam kehidupan kita sehari-hari untuk semua umat non muslim yang inggin memeluk islam.

Maka dari penjelasan diatas dapat kita simpulkan bahawa adanya representasi pendidikan spiritual islam dalam novel lauf mahfuz dengan realita realita pendidikan spiritual islam dimasyarakat.

\section{Salat}

"Manifestasi hablum-minallah adalah sebagai mana diperintahkan Tuhan, yaitu dengan mendirikan shalat." (Nugroho, $2012: 107)$

Dari penjelasan syekh Abu Salaf kepada Panji dan Menuk mengatakan shalat adalah sebagai perantara antara manusia kepada tuhannya, (Hablumminallah). sebagian orang yang mengartikan shalat disini hanya secara bahasa, yang mana secara bahasa shalat berarti berdoa. Akan tetatpi secara istilah shalat berarti beberapa ucapan dan perbuatan yang dimulai dengan takbir dan diakhiri dengan salam, yang dengannya kita beribadah kepada Allah menurut syarat dan rukun yang telah ditentukan. Dari kalimat diatas sangatlah jelas bahwa shalat itu dikerjakan bukan hanya diucapkan dengan bahasa lain adalah mendirikan shalat bukan mengucapkan shalat. Ketika sesdeorang mendirikan shalat maka shalat mempunyai sharat, sah, dan rukun shalat. Iniolah representasi pendidikan spiritual islam dengan realita pendidikan spiritual dimasyarakat.

\section{Zakat}

"Zakat dilakukan dengan menyisihkan harta bagi kepentingan masyarakat, terutama untuk diberikan kepada sesama umat yang kurang mampu." (Nugroho, $2012: 122)$

Syekh Abu Salaf menjelaskan kepada Panji dan menuk bahwa zakat merupakan salah satu peraktek nyata hablum-minannas yang mana hablumminannas tersebut secara langsung berdampak terhadap hubungan keimanan seorang muslim kepada tuhanya (hablumminallah). Praktek Zakat ini sering kita jumpai pada saat bulan ramadlan sebelum hari raya idul fitri yang disebut zakat fitrah, dimana seseorang akan mensisihkan hartanya yang berupa makanan pokok (di Indonesia beras) yang 
akan diberikan kepada orang-orang tertentu menurut sara'.

Di pembahasan diatas jelas kita fahami tentang adanya representasi zakat yang ada dalam novel Lauh mahfuz karya nugroho Suksmanto dengan zakat yang dilakukan kehidupan bermasyarakat.

\section{Puasa}

"Puasa Ramadan adalah upaya melatih diri untuk menahan hawa nafsu untuk membakar dosa-dosa, yaitu dengan menyucikan diri dari hal-hal yang mengotori hati." (Nugroho, $2012: 370$ )

Syekh Abu Salaf menjelaskan kepada Panji dan Menuk tentang puasa, yang mana puasa termasuk pekerjaan yang bisa menghapus dosa dengan kata lain ketika manusia menjalankannya akan mendapat ampunan dari dosa-dosa yang ringan. Puasa ramadhan merupakan puasa fardlu yang dikerjakan satu bulan penuh selama 30 hari di bulan ramadlan (bulan Arab). Untuk menyempurnakan puasa ramadhan, seorang muslim disunahkan mengerjakan shalat idul fitri. Hal seperti ini sama seperti apa yang kita lakukan disetiap tahunya, melakukan puasa dan meryakan di hari raya idul fitri.

Maka dari penjelasan diatas dapat kita simpulkan bahawa adanya representasi pendidikan spiritual islam dalam novel lauf mahfuz dengan realita realita pendidikan spiritual islam dimasyarakat.

\section{Haji}

"Tanggal 10 Zulhijah adalah hari raya Haji (Idul Adha) yang merupakan puncak pelaksanaan salah satu rukun Islam setelah para jamaah turun dari Padang Arafah." (Nugroho, 2012 :421)

Panji memahami tentang penjelasan sekh Abu Salaf tentang ibadah haji yang mana Pada tanggal tersebut seluruh umat islam sedunia berkumpul jadi satu di padang arafah guna menunaikan wukuf . sabiq (tt. 211) menyatakan bahwa etika wukuf diarafah ialah menjaga kesucian sedapat mungkin, menghadap kiblat, istigfar, mengingat allah, berdo'a dengan khusu', merendahkan hati dan mengangkat kedua tangan.

Maka dari penjelasan diatas dapat kita simpulkan bahawa adanya representasi pendidikan spiritual islam (ibadah Haji) dalam novel lauf mahfuz dengan realita realita pendidikan spiritual (ibadah Haji) islam dimasyarakat

\section{SIMPULAN DAN SARAN}

Dari hasil penelitian yang telah dilakukan yang menggunakan dua rumusan masalah maka dapat diambil dua kesimpulan sebagai bertikut:

Hakikat perndidikan spiritula dalam novel lauf mahfuz karya nugroho suksmanto meliputi hakikat pendidikan akidah yang mana terdapat enam unsur yaitu : (1) iman kepada Allah, (2) iaman kepada malaikat Allah, (3) iman kepada rasulullah, (4) iman kepada kitap Allah, (5) iman kepada qada dan qadar, (6) iman kepada hari kiamat, dan hakikat pendidikan syariat yang mempunyai lima unsur yaitu: (1) syahadah, (2) shalat, (3) zakat, (4) puasa, (5) haji bila mampu.

Representasi hakikat Pendidikan spiritual yang terkandung dalam novel Lauf Mahfuz karya Nugroho Suksmanto dengan realita pendidikan spiritual dimasyarakat mempunyai kaitan yang sama dengan Pendidikan syariat Yaitu: 1) syahadah, (2) shalat, (3) zakat, (4) puasa, (5) haji bila mampu.

Berdasarkan beberapa kesimpulan yang diuraikan diatas, berikut ini akan dikemukakan saran-saran sebagai berikut, penelitian ini dapat dijadikan sebagai masukan atau refrensi dalam penelitian sastra, hakikat pendidikan, hakikat spiritual islam. hasil penelitian ini dapat menambah khasanah pengetahuan pembaca mengenai sastra khususnya dalam hakikat pendidikan spiritual islam . Membangun kerangka berfikir aplikatif 
yang sesuai dalam kondisi saat ini.Bagi peneliti, penelitian ini dapat menjadi suatu pengalaman dalam mengapresiasi karya sastra. Bagi siswa dan mahasiswa, hasil penelitian ini dapat meningkatkan daya apresiasi siswa dan mahasiswa terhadap sebuah novel. Bagi masyarakat, hasil penelitian ini dapat dijadikan sebagai kontrol akidah untuk mendekatkan diri pada sang pencipta, dan melaksanakan kewajiban sebagai mahluk (hablumminallah) dan sesama manusia (hablumminannas).Hasil penelitian ini dapat di sarankan untuk kegiatan keilmuan dan pembelajaran sastra, akidah dan syariat (Spiritual Islam).

\section{DAFTAR PUSTAKA}

Bisri, Mustofa. 1997. Fikih Keseharian. Rembang: Yayasan Pendidikan Al ibriz.

Kementrian Agama RI. 2010 . Al-Quran dan Terjemahan. Jakarta Selatan: Wali Oasis Terrace Reciden.
Kurnia, M R. 2015. Menjadi Pembela Islam. Bogor: Al Azhar Press

Engkoswara dan Komariah Aan. 2012. Administrasi Pendidikan. Bandung: CV Alfabeta.

Iskandar, Arif B. 2015. Materi Dasar Islam (Islam Mulai Akar Hingga Daunya. Bogor: Al-Azhar Press.

Moleong, Lexy J. 2005. Metodologi Penelitian Kualitatif. Bandung: PT Remaja Rosda Karya

Muslim, Imam. tt. Sahih Muslim. Surabaya: Al Hidayah

Muctar Heri Jauhari. 2008. Fikih Pendidikan. Bandung: PT Remaja Rosdakarya.

Qamis kamil, Muhammad. 2014. Halal Haram Dalam Islam. Depok: Mutiara Allahma Utama.

Sabiq, Sayyid. tt. Fiqih Sunnah. Depok: Fathan media prima. 